\title{
Metabolism of Immunoglobulin E in Patients with Markedly Elevated Serum Immunoglobulin E Levels
}

\author{
Stephen C. Dreskin, Paul K. Goldsmith, ${ }^{\star}$ Warren Strober, Lauren A. Zech, ${ }^{\ddagger}$ and John I. Gallin \\ Bacterial Diseases Section, Laboratory of Clinical Investigation, National Institute of Allergy and Infectious Diseases; ${ }^{*}$ National Institute \\ of Diabetes, Digestive and Kidney Diseases; and ${ }^{\ddagger}$ Laboratory of Theoretical Biology, National Cancer Institute, \\ National Institutes of Health, Bethesda, Maryland 20892
}

\begin{abstract}
The metabolism of human IgE was studied in normals, severe atopics, and patients with the hyperimmunoglobulin E-recurrent infection (HIE; Job's) syndrome to determine whether IgE metabolism is altered in patients with marked elevation of serum IgE. Purified polyclonal ${ }^{125} \mathrm{I}$-IgE was administered intravenously and serial plasma and urine samples were obtained. After analysis, the metabolic data support previously published evidence that IgE (at concentrations found in normal individuals) is catabolized at a higher fractional rate than other immunoglobulins and is catabolized by both an intravascular and an extravascular pathway. In addition, the data show that the fractional catabolic rate for IgE is significantly less for the atopic patients (mean \pm SEM $=0.20 \pm 0.01$ ) and for the HIE patients $(0.15 \pm 0.02)$ than for the normal volunteers $(0.52 \pm 0.06 ; P<0.01)$ and is inversely related $(r=-0.851 ; P<0.001)$ to the serum IgE concentration. These findings have specific importance in showing that decreased fractional catabolic rate contributes substantially to elevation of $\mathrm{IgE}$ in atopic and HIE patients. In addition, the findings have general significance in that they lead to a unifying hypothesis of immunoglobulin catabolism.
\end{abstract}

\section{Introduction}

Immunoglobulin $\mathrm{E}$ has the unique biologic property of mediating antigen-dependent immediate hypersensitivity reactions via binding to high-affinity Fc-epsilon receptors on mast cells and basophils (1). Previous studies of IgE metabolism (2-6) established that IgE is more slowly synthesized and more rapidly catabolized than other immunoglobulin classes (7). It is cleared from the plasma at a rate $\sim 10$ times that of $\operatorname{IgG}, 4$ times that of $\operatorname{IgM}$, and $\operatorname{IgA}$ and 2 times that of $\operatorname{IgD}$. Other conclusions of earlier metabolic studies were that IgE, unlike IgG, IgA, or IgM is subject to at least two catabolic pathways (6) and that at very high IgE concentrations (in patients with IgE myeloma), IgE catabolism is greatly reduced. In the following study we have attempted to explore further the metabolism of IgE by examining IgE turnover in patients with a wide spectrum of IgE concentrations, including patients with elevated IgE levels associated with severe atopic disease and patients with the hyperimmu-

Address reprint requests to Dr. Gallin, NIAID, NIH, BLDG 10, Rm. $11 \mathrm{~N}-114$, Bethesda, MD 20892. Dr. Dreskin's present address is National Institute of Arthritis, Musculoskeletal and Skin Diseases, Building 10, National Institutes of Health, Bethesda, MD 20892.

Received for publication 2 December 1986.

1. Abbreviations used in this paper: FCR, fractional catabolic rate; HIE, hyperimmunoglobulin E-recurrent infection (Job's) syndrome.

The Journal of Clinical Investigation, Inc.

Volume 79, June 1987, 1764-1772 noglobulin E-recurrent infection (HIE; Job's) syndrome (8). Other important aspects of the current investigation are the use of polyclonal IgE isolated from a patient with HIE rather than the use of the myeloma proteins previously studied and the application of advanced computer analysis with the SAAM-27 program (9) for data analysis.

The data obtained support earlier findings (6) that IgE is catabolized at a higher fractional rate than are other immunoglobulins and is catabolized by both an extravascular and intravascular pathway. A new finding is that IgE is cleared from the plasma more slowly (decreased fractional catabolic rate [FCR]) by both groups of patients with markedly elevated IgE concentrations and that (for all subjects) the rate of clearance is inversely related to the serum IgE level. In addition, the fractional clearance of IgE in patients with markedly elevated IgE is similar to that seen for other immunoglobulins under limiting conditions. Finally, although patients with markedly elevated IgE have a substantial increase in the mass of extravascular IgE, the proportion of their total IgE that is in the extravascular space is decreased compared with normals and is inversely related to the serum IgE concentration. These findings, in the context of previous studies have led us to a unifying hypothesis of immunoglobulin catabolism.

\section{Methods}

Patients. Individuals included in this study were as follows: $(a)$ Five patients with HIE (IgE, geometric mean $X / \div$ relative $\mathrm{SEM}=34,500$ $\mathrm{ng} / \mathrm{ml} \times / \div 1.6$ ) were reported previously by Donabedian and Gallin (8) as patients $3,7,10,12,13$, and 16 . At the time of study, three of the HIE patients were in relatively good health, whereas two were recovering from serious Staphylococcus aureus infections; all were clinically stable. (b) Five patients had severe atopic disease (IgE, geometric mean $\times / \div$ relative $\mathrm{SEM}=11,880 \mathrm{ng} / \mathrm{ml} \times / \div 3.6$ ). This group included two patients with severe (10) atopic dermatitis (using topical steroids), one patient with allergic bronchopulmonary aspergillosis (prednisone $25 \mathrm{mg}$ QOD), and one patient with allergic asthma (prednisone $17.5 \mathrm{mg}$ QOD). At the time of study, all of the atopic patients were in generally good health (the two patients taking oral steroids were studied $48 \mathrm{~h}$ after a dose of prednisone with the subsequent dose delayed until $4 \mathrm{~h}$ after injection of the tracer). (c) Five normal volunteers (IgE, geometric mean $\times / \div$ relative SEM $=70 \mathrm{ng} / \mathrm{ml} \times / \div 2.1$ ) were also studied. Three had negative histories of allergic disease, two had a history of mild seasonal rhinitis, and none had atopic dermatitis. None of the 14 individuals studied had evidence of parasitic infection.

Immunosorbents. (a) Immunoglobulins: human IgG (Cappel Laboratories, West Chester, PA), human IgA (Jackson Immunoresearch, Avondale, PA), and human IgM (Jackson Immunoresearch) were (without further purification) covalently linked to cyanogen bromide-activated Sepharose (Pharmacia Fine Chemicals, Piscataway, NJ); IgE (PS)-Sepharose was prepared as previously described (11). (b) Anti-immunoglobulins: goat anti-human IgE was affinity purified on an IgE (PS) column as previously described (12), further purified by cross-adsorption by passage over Sepharose-linked human IgG, IgA, and IgM, and finally covalently linked to cyanogen bromide-activated Sepharose. IgG fractions 
of goat anti-human IgG (Cappel Laboratories) and goat anti-human IgA (Cappel Laboratories) were purified by cross-adsorption onto IgE(PS)Sepharose and were then covalently linked to cyanogen bromide-activated Sepharose.

Immunoglobulin assays. IgG, IgA, IgM, IgD, and IgE concentrations were quantified via enzyme-linked immunosorbent assays (ELISA) previously described (11). IgE was also assayed using the Phadezym IgE kit (Pharmacia Fine Chemicals).

Protein concentration. Protein concentration was determined by Coomassie Blue (13) using human IgG as standard.

IgE purification. IgE was purified from the plasma of a patient with HIE (patient 5 in reference 8). $500 \mathrm{ml}$ of fresh plasma was collected (after an overnight fast) and was added to $50 \mathrm{ml}$ of $100 \mathrm{mM}$ EDTA (pH 7.0). This material was then passed over a 40-ml volume of Sepharoselinked, affinity-purified, goat anti-human IgE. The column was then washed with phosphate-buffered saline (PBS) and the absorbed material was desorbed with $3 \mathrm{M} \mathrm{MgCl}_{2}$, pH 4.7. The eluate was dialyzed overnight against sterile PBS and concentrated. The material obtained was further purified by sequential cross-absorbtion with goat anti-human IgG-Sepharose and goat anti-human IgA-Sepharose, followed by fractionation on a high-pressure liquid chromatography (HPLC) TSK-3000 column. The final material was then concentrated and frozen until used. All steps except the affinity purification, the HPLC, and the iodination were performed at $4^{\circ} \mathrm{C}$. The purified IgE preparation contained $<0.02 \%$ IgG, IgA, IgM, or IgD. $85 \%$ of the protein was immunoreactive with antiIgE in the ELISA assays. A 7.5\% polyacrylamide gel of the IgE preparation (after reduction in 5\% [vol/vol] 2-mercaptoethanol) is shown in Fig. 1 (lane $d$ ); commercially available IgG, IgA, and IgM are shown in lanes $a, b$, and $c$, respectively.

Iodination. 70-170 $\mu \mathrm{g}$ of purified IgE in $100 \mathrm{mM}$ PBS (pH 7.0) was reacted with $0.3-0.5 \mathrm{mCi}$ of ${ }^{125} \mathrm{I}$ (New England Nuclear, Boston, MA) $(17 \mathrm{mCi} / \mathrm{mg}$ ) in the presence of five washed Iodobeads (Pierce Chemical Co., Rockford, IL) for $15 \mathrm{~min}$ at room temperature and then passed over a prepacked Sephadex G-25 column preequilibrated with $1 \%$ human

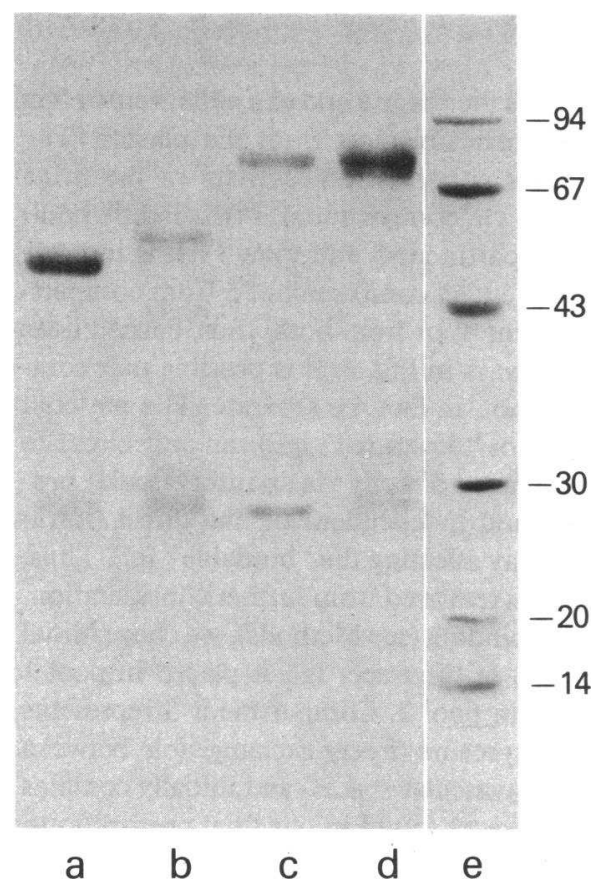

Figure 1. 25-50 $\mu \mathrm{g}$ of commercially obtained human IgG (lane $a$ ), IgA (lane $b$ ), IgM (lane $c$ ), affinity-purified human polyclonal IgE (lane $d$ ) and molecular weight standards in thousands (Pharmacia Fine Chemicals, lane $e$ ) were reduced by boiling for $3 \mathrm{~min}$ in $5 \%$ (vol/vol) 2-mercaptoethanol and applied to a $7.5 \%$ polyacrylamide gel. Samples were stained with Coomassie Blue. serum albumin in PBS after which the void volume was collected and sterile filtered. The iodinated IgE was sampled for pyrogen and sterility testing by the Bureau of Biologics, National Institutes of Health. Unit dose samples of sterile, pyrogen-free ${ }^{125} \mathrm{I}-\mathrm{IgE}$ were frozen at $-70^{\circ} \mathrm{C}$ for 2-8 wk and thawed immediately before use. The specific activity was 1 $\mu \mathrm{Ci} / \mu \mathrm{g} ; 5 \%$ of the counts were not protein bound. Evaluation of two of our preparations by Dr. T. Ishizaka (personal communication) revealed that $65 \%$ of the counts bound specifically to cultured human basophils in vitro.

Study protocol. The study protocol (84-I-195) was approved by the National Institute of Allergy and Infectious Diseases human subject review committee, the National Institutes of Health radioactive drug research committee, and the National Institutes of Health radiation safety committee. All subjects gave informed consent. Individuals undergoing study received $0.15 \mathrm{ml}$ of saturated potassium iodide solution three times a day beginning the night before the study and continuing until $\sim 1 \%$ of the initial plasma radioactivity remained. The study was initiated by intravenous injection of 4-12 $\mu \mathrm{Ci}$ of labeled $\mathrm{IgE}$ in $0.5 \%$ human serum albumin. Plasma samples $(5 \mathrm{ml})$ were obtained at 10,30 , and $60 \mathrm{~min}$, and $2,4,8$, and $12 \mathrm{~h}$ after injection and then daily. Complete urine collections were obtained each $24 \mathrm{~h}$ throughout the study. Two patients (one with atopic dermatitis and one with HIE) were unable to collect adequate urine samples. The analysis for these patients was therefore limited. The plasma and urine samples as well as a measured aliquot of the injected dose were counted simultaneously. For analysis of circulating ${ }^{125} \mathrm{I}$-IgE, sera were obtained $10 \mathrm{~min}, 8$ and $24 \mathrm{~h}$ after injection of ${ }^{125} \mathrm{I}$ $\mathrm{IgE}$ and were immediately frozen at $-80^{\circ} \mathrm{C}$.

Data analysis. Data for each patient were analyzed separately. Plasma volume and total circulating $\mathrm{IgE}$ were determined as previously described (6). Compartmental analysis was performed with the use of the simulation analysis and modeling (SAAM-27) program (9) of Berman et al. (15) and addressed via the CONSAM communications software (16) utilizing a DEC 11/780 computer (Digital Equipment Corp., Maynard, MA) (1719). This analysis allows the estimation of metabolic parameters using alternative compartmental models. Fitting is carried out by iterative adjustment of parameters so as to minimize least square differences between observed and calculated values. Both the plasma die-away curve and the urine excretion curves are utilized by the SAAM program to generate the best fit for all the data. Using this program, one can estimate (17, 18) for a chosen model, the FCR, the absolute catabolic rate, the synthetic rate, the size of each compartment, and the intercompartmental rate constants.

Statistical analysis. All summary data are expressed as either the arithmetic mean \pm SEM or the geometric mean $\times / \div$ the relative SEM. Data were evaluated by the use of a two-tailed Student's $t$ test or by Spearman rank-correlation coefficients.

\section{Results}

IgE was purified from a patient with the HIE syndrome, iodinated, and then used in the metabolic studies to be described. As mentioned in Methods, $65 \%$ of the counts bound to cultured human basophils (Ishizaka, T., personal communication) and $5 \%$ were composed of free iodine. To explore further the integrity of the ${ }^{125} \mathrm{I}$-IgE used in these studies, the distribution of ${ }^{125} \mathrm{I}$ was analyzed on HPLC before (Fig. $2 A$ ) and, by chromatography of whole serum, at various times after injection (Fig. 2, $B-D$ ). As can be seen, the ${ }^{125} \mathrm{I}-\mathrm{IgE}$ was homogeneous before injection and circulated in an unaltered state after injection. This was the case in three of three normals and three of four patients with elevated IgE (data not shown). However, in one of three HIE patients examined, $\sim 25 \%$ of the radioactive material eluted in the void volume. This may represent IgE immune complexes.

The ${ }^{125} \mathrm{I}$-IgE was then utilized in metabolic studies. The primary data obtained were used to generate a composite plasma and a composite cumulative urine excretion curve for each of 


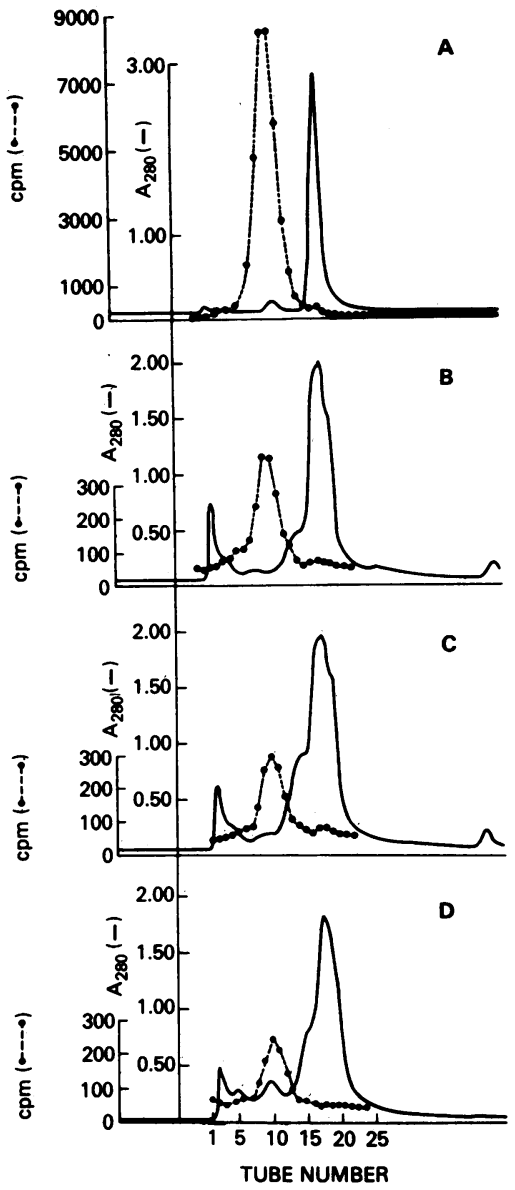

Figure 2. HPLC of ${ }^{125}$ IIgE on a TSK-3000 column equilibrated with $50 \mathrm{mM}$ phosphate buffer, pH 7.0. (A) 1.0 $\mathrm{ml}$ of iodinated human $\operatorname{IgE}(5 \mu \mathrm{g}$ at $1 \mu \mathrm{Ci} / \mu \mathrm{g})$ in $0.5 \%$ human serum albumin $(B-D) ; 1.0 \mathrm{ml}$ of serum obtained $(B) 10$ $\min ,(C) 8 \mathrm{~h}$, and $(D)$ $24 \mathrm{~h}$ after administration of 4-5 $\mu \mathrm{Ci}{ }^{125} \mathrm{I}-\mathrm{IgE}$ to $(B, C)$ normal volun teers or $(D)$ a patient with HIE.

the groups studied. As can be seen in Fig. 3, the atopics and the HIE patients clear the radioactivity more slowly from the plasma (Fig. $3 \mathrm{~A}$ ) and excrete it more slowly into the urine (Fig. $3 \mathrm{~B}$ ). Thus, the percentage of the injected dose remaining at day 6 in the plasma of both the HIE patients and the atopic patients is significantly less than that remaining in the normal volunteers ( $P<0.05$ for atopic; $P<0.001$ for HIE). In a complementary fashion, the cumulative excretion of radioactivity at day 6 is greater in the normal volunteers than for the patients with HIE $(P<0.01)$.

Utilizing the SAAM-27 program, we evaluated several compartmental models for their capacity to fit the primary metabolic data. Of the models studied, only the model shown in Fig. 4 gave a good fit for the data from all three patient groups. Omission of any component resulted in a larger sum of square difference between the observed and calculated values.

In this model, pools 1 and 2 represent IgE-bound radioactivity in the plasma. These pools are different in that pool 1 contains (in the initial conditions) the fraction of ${ }^{125} \mathrm{I}-\mathrm{IgE}$ that could bind human basophils in vitro ("native" IgE) whereas the fraction of ${ }^{125} \mathrm{I}-\mathrm{IgE}$ that could not bind to these cells ("denatured" $\mathrm{IgE}$ ) is placed in pool 2. The material in pool 1 can be catabolized by a direct (intravascular) pathway into the iodide pool (pool 3), can exchange with an extravascular exchangeable compartment (pool 4), or can be catabolized irreversibly via an indirect (extravascular) pathway (pool 5). Specific information concerning the extravascular compartments 4 and 5 is limited in that samples were obtained only from the plasma and the urine. Ra-

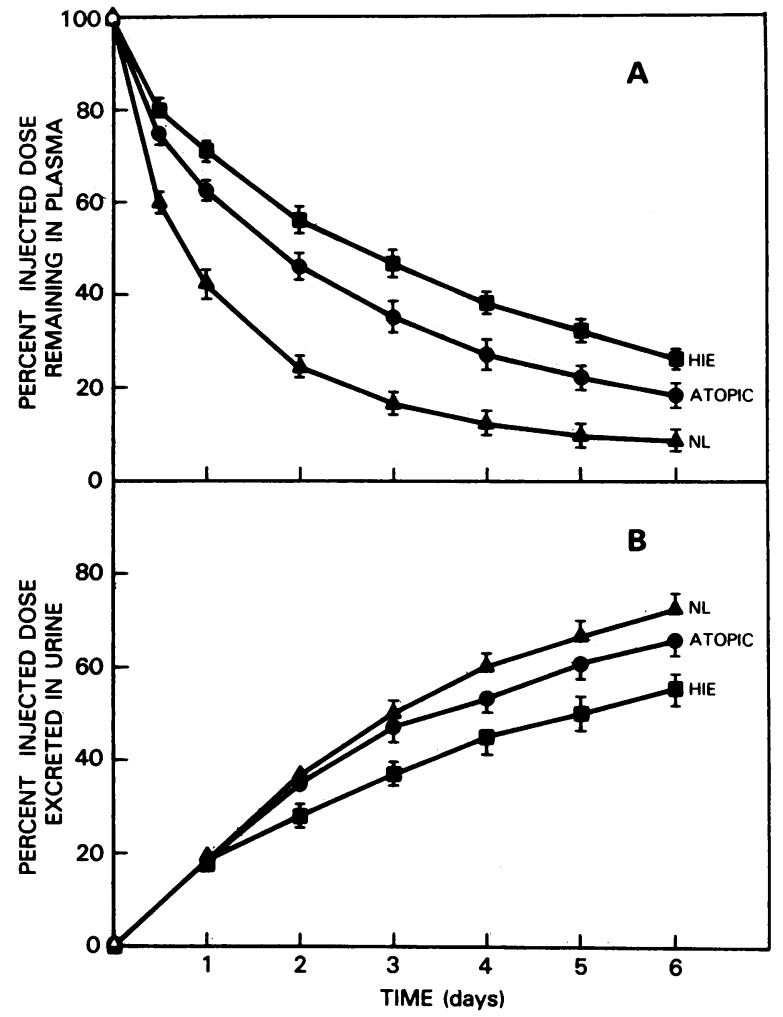

Figure 3. Composite graph of $(A)$ plasma die-away and $(B)$ cumulative urine excretion curves. The data are expressed as a percentage of injected dose. (Triangles) Normal volunteers, (circles) patients with severe atopy, (squares) patients with HIE. For $A$ : atopic vs. normal $(P$ $<0.05)$; HIE vs. normal $(P<0.001)$; HIE vs. atopic $(P<0.05)$. For $B$ : atopic vs. normal (NS); HIE vs. normal $(P<0.01)$; HIE vs. atopic (NS).

dioactivity in pool 1 leaves the plasma and can either return (via compartment 4 ) or is irreversibly lost from the plasma. The latter component appears either as radioactivity in the urine (compartment 6) quickly via compartment 3 (the iodide pool) or after a delay (via compartment 5 and then 3 ). It is indeterminant whether material enters compartment 5 from compartment 1 , from compartment 4 , or from both; thus, dashed lines are drawn for these pathways in Fig. 4. It is possible that compartments 4 and 5 may not, in fact, be separate. The material in pool 2 ("nonbindable" or "denatured" IgE) can only circulate in the plasma and be degraded directly via an intravascular process that is faster than, and independent of, the direct (intravascular) catabolic pathway affecting the "bindable" IgE. Thus, the nonbindable ${ }^{125} \mathrm{I}$-IgE is removed from further consideration. Based on the data of IgE binding (see Methods), we chose initial conditions such that $65 \%$ of the tracer IgE is placed in pool 1 and $30 \%$ of the tracer is in pool 2. Compartment 3 represents free iodide or iodinated tyrosine (freely exchangeable between the intravascular and extravascular spaces) and initially contains the remaining $5 \%$ of the tracer found in our final preparations.

Representative computer plots of observed and calculated data from a single normal volunteer are shown in Fig. 5. Fig. 5 $A$ shows the radioactivity $\left({ }^{125} \mathrm{I}-\mathrm{IgE}\right)$ in $0.5 \mathrm{ml}$ of plasma as a fraction of the injected dose and Fig. $5 B$ shows the fraction of the injected counts recovered in the urine each day (note that Fig. $5 B$ displays fractional excretion of ${ }^{125} I$ and not cumulative urine data as shown in Fig. $3 \mathrm{~B}$ ). As can be seen, there is a rise 


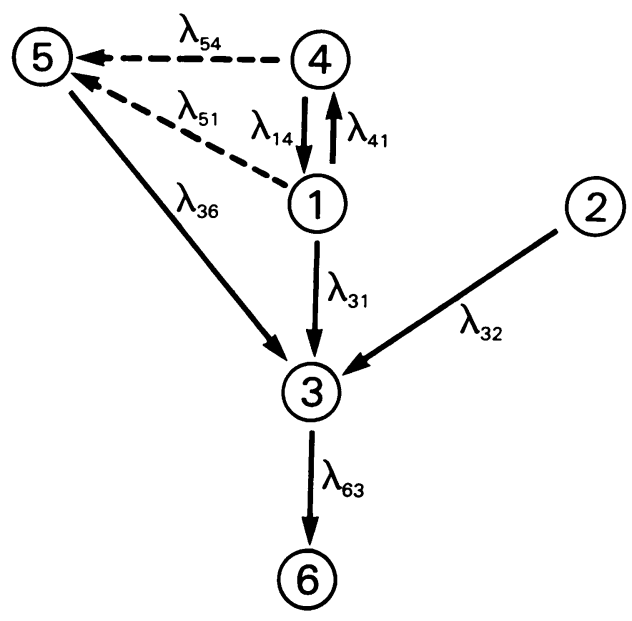

Figure 4. Current model of IgE catabolism. For the modeling analysis described in the text, compartment 1 represents the intravascular native IgE. Material circulating in this pool is free to bind reversibly to an extravascular binding site (compartment 4 ) and to an extravascular catabolic site (compartment 5). ${ }^{125} \mathrm{I}$-IgE that is catabolized via either the direct (intravascular) pathway directly out of compartment 1 or by a delay (indirect, extravascular) pathway via compartment 5 will yield free iodine $\left({ }^{125} \mathrm{I}\right)$ in compartment 3 (the free iodine pool). This material rapidly appears in the urine (compartment 6). Compartment 2 represents the portion of ${ }^{125} \mathrm{I}-\mathrm{IgE}$ that was injected intravascularly but does bind to the reversible binding sites (and presumably does not behave as native IgE). This material is modeled to be catabolized at a rate faster than, but independent of, the "bindable" IgE in compartment 1 .

in the observed fractional ${ }^{125} \mathrm{I}$ excretion at day 3 (Fig. $5 \mathrm{~B}$ ). This rise is a consistent finding in virtually all studies and is the feature of the metabolic data that mandated the need for a delay catabolic pathway through pool 5 .

IgE metabolic data for each subject are listed in Tables IIII. Table I lists the serum IgE, the intravascular IgE, the FCR, and the IgE synthetic rate. The intravascular IgE is the product of the serum IgE concentration and the plasma volume. The FCR represents the sum of the rate constants governing the movement of label irreversibly from compartment 1 as defined by the expression:

$\mathrm{FCR}=\lambda_{31}+\lambda_{51}$,

where $\lambda_{31}$ and $\lambda_{51}$ are rate constants for the movement of label from pool 1 to pools 3 and 5 , respectively. In the steady state, the synthetic rate is equal to the absolute catabolic rate and thus was obtained by multiplying the intravascular IgE concentration by the FCR. It can be seen that the FCR in normals $(0.52 \pm 0.06)$ is significantly larger than for atopic patients $(0.20 \pm 0.01 ; P$ $<0.01)$ or for HIE patients $(0.15 \pm 0.02 ; P<0.001)$, whereas the difference between the FCRs for atopics and HIE patients is not statistically significant. In comparing individual FCRs with individual serum IgE concentrations, the FCR is inversely related (Spearman rank-correlation coefficient) to the serum IgE levels ( $r=-0.851 ; P<0.001)$; this is shown graphically in Fig. 6 . Finally, the synthetic rate data reveal that, on the average, patients with markedly elevated IgE have a lower IgE synthetic rate (60\% less for atopics; $71 \%$ less for HIE) than would be predicted on the basis of elevated serum IgE alone (given a constant

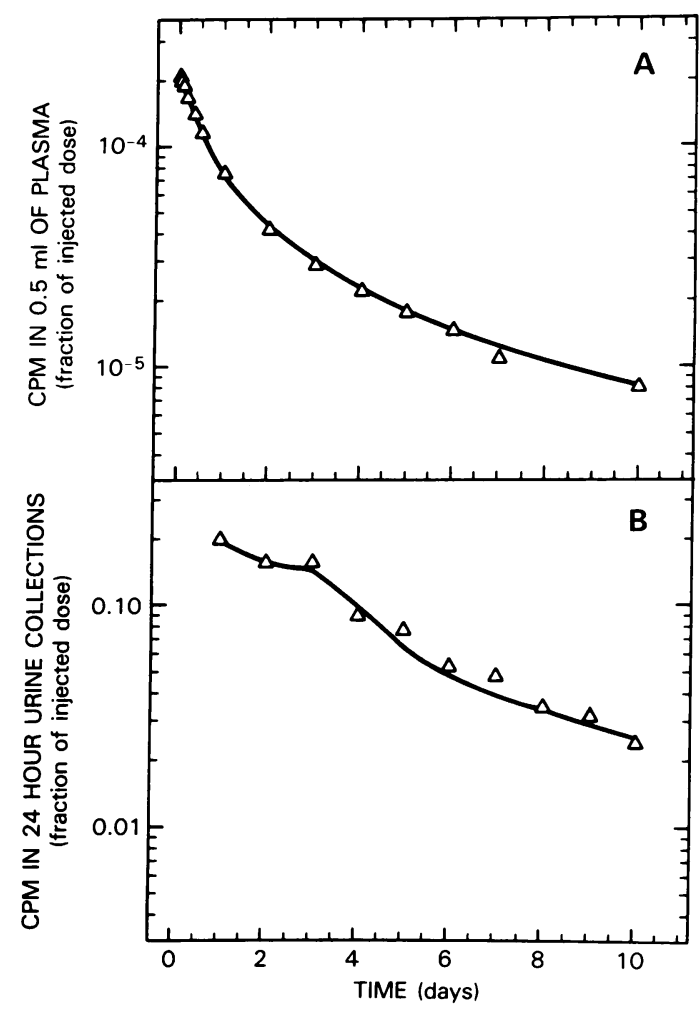

Figure 5. Observed and calculated data from a single normal volunteer. $(A)$ Radioactivity in $0.5 \mathrm{ml}$ of plasma as a fraction of the injected dose. (B) Fraction of the injected dose excreted in the urine each $24 \mathrm{~h}$. (Triangles) Observed values. (Continuous line) Envelope of the observed values (using the model described in Fig. 4).

FCR). Thus, for an individual patient (e.g. S.W.), the measured IgE synthetic rate can be as low as $15 \%$ of that predicted on the basis of the FCR found in normals.

Table II lists the total body IgE, the intravascular IgE, the extravascular IgE, and the percentage of the total IgE that is extravascular. These values are derived from measurement of the mass of $\mathrm{IgE}$ in pool 1 and determination of the steady state rate constants. The latter $\left(\lambda_{41}, \lambda_{14}, \lambda_{51}, \lambda_{35}\right)$ are derived from the compartmental model (Fig. 4). The following formulas were used to determine the distribution of IgE:

$\operatorname{Mass}(1) \lambda_{41}=\operatorname{mass}(4) \lambda_{14} ;$
$\operatorname{mass}(5) \lambda_{35}=\operatorname{mass}(1) \lambda_{51} ;$

and, from Eqs. 2 and 3,

$\frac{\text { extravascular mass }}{\text { intravascular mass }}=\frac{\operatorname{mass}(4)+\text { mass }(5)}{\operatorname{mass}(1)}=\frac{\lambda_{41}}{\lambda_{14}}+\frac{\lambda_{51}}{\lambda_{35}}$.

As can be seen in Table II, the total, intravascular, and extravascular IgE levels in the patients with markedly elevated IgE are greatly increased compared with the levels in the normal volunteers and, considering all subjects, are directly related to the serum IgE levels $(r=0.97 ; P<0.001)$. In contrast, the percentage of the IgE that is extravascular ranges from $60-76 \%$ in normal volunteers to $24-54 \%$ in with HIE and is inversely related to the serum IgE level $(r=-0.810 ; P<0.01)$; this is shown graphically in Fig. 7.

It is useful to calculate an average "half-life" $\left(t_{1_{2}}\right)$ for each 
Table I. Metabolism of IgE

\begin{tabular}{|c|c|c|c|c|c|c|c|}
\hline Patient group & Patient & Serum IgE & Intravascular IgE & FCR & Synthetic rate & $\begin{array}{l}\text { Predicted } \\
\text { synthetic rate }\end{array}$ & Synthetic rate \\
\hline & & $\mu g / m l$ & $\mu g / k g$ & & $\mu g / \mathrm{kg}$ per $d$ & $\mu g / k g$ per $d$ & \% predicted \\
\hline \multirow[t]{5}{*}{ Normals } & L.F. & 0.02 & 1.21 & 0.56 & 0.68 & 0.62 & 108.54 \\
\hline & M.H. & 0.27 & 12.02 & 0.63 & 7.54 & 6.19 & 121.75 \\
\hline & M.N. & 0.02 & 1.09 & 0.27 & 0.29 & 0.56 & 52.04 \\
\hline & R.L. & 0.02 & 0.89 & 0.50 & 0.45 & 0.46 & 97.48 \\
\hline & H.G. & 0.63 & 26.84 & 0.62 & 16.64 & 13.82 & 120.39 \\
\hline Geometric mean & & 0.07 & 3.28 & & 1.62 & 1.69 & \\
\hline$X / \div$ relative SEM & & 2.11 & 1.88 & & 2.07 & 1.88 & \\
\hline Arithmetic mean & & & & 0.52 & & & 100.04 \\
\hline \pm 1 SEM & & & & 0.06 & & & 11.43 \\
\hline \multirow[t]{4}{*}{ Atopics } & D.M. & 21.83 & 1090.00 & 0.18 & 198.38 & 561.35 & 35.34 \\
\hline & G.A. & 90.52 & 3980.00 & 0.19 & 772.12 & 2049.70 & 37.67 \\
\hline & R.H. & 5.58 & 280.00 & 0.21 & 59.64 & 144.20 & 41.36 \\
\hline & C.H. & 1.80 & 70.00 & 0.23 & 15.82 & 36.05 & 43.88 \\
\hline Geometric mean & & $11.88^{*}$ & $540.00^{*}$ & & $109.64^{*}$ & 278.10 & \\
\hline$X / \div$ relative SEM & & 2.33 & 2.12 & & 2.05 & 2.12 & \\
\hline Arithmetic mean & & & & $0.20^{\ddagger}$ & & & $39.56^{\ddagger}$ \\
\hline $\pm 1 \mathrm{SEM}$ & & & & 0.01 & & & 1.65 \\
\hline \multirow[t]{5}{*}{ HIE } & C.C. & 20.88 & 970.00 & 0.19 & 182.36 & 499.55 & 36.50 \\
\hline & C.S. & 71.54 & 3850.00 & 0.13 & 504.35 & 1982.75 & 25.44 \\
\hline & K.Z. & 10.00 & 580.00 & 0.20 & 117.16 & 298.70 & 39.22 \\
\hline & S.W. & 23.72 & 520.00 & 0.08 & 41.08 & 267.80 & 15.34 \\
\hline & T.L. & 137.97 & 5790.00 & 0.15 & 891.66 & 2981.85 & 29.90 \\
\hline Geometric mean & & $34.50^{*}$ & $1455.00^{*}$ & & $208.57^{*}$ & 749.33 & \\
\hline$X / \div$ relative SEM & & 1.60 & 1.56 & & 1.57 & 1.56 & \\
\hline Arithmetic mean & & & & $0.15^{*}$ & & & $29.28^{*}$ \\
\hline \pm 1 SEM & & & & 0.02 & & & 3.80 \\
\hline
\end{tabular}

* $P<0.001$ compared with normals. ${ }^{\ddagger} P<0.01$ compared with normals.

subject. To do this one can determine the slope $(\lambda)$ for an average single exponential decay:

$t_{1 / 2}=(\ln 2) / \lambda$.

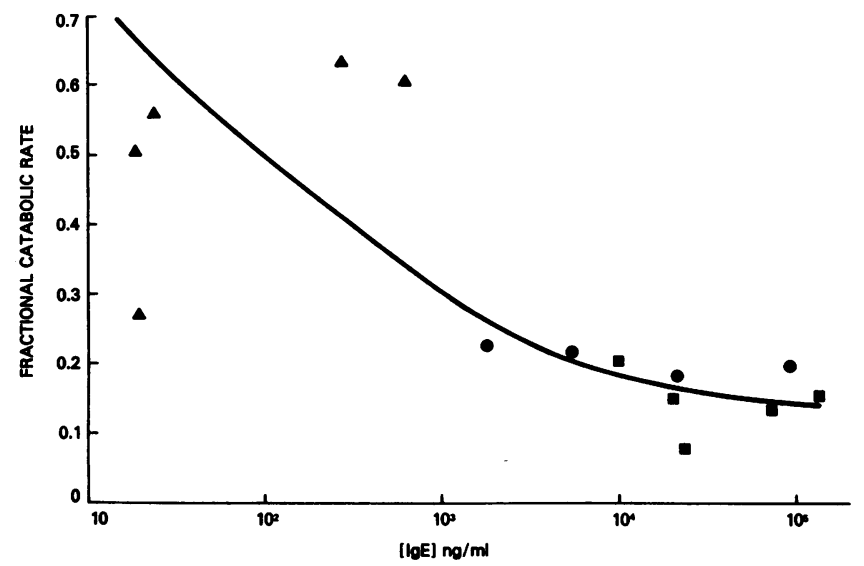

Figure 6. FCR as a function of serum IgE levels. (Triangles) Normal volunteers, (circles) patients with severe atopy, (squares) patients with HIE. Spearman rank-correlation coefficient $r=-0.851 ; P<0.001$. A line is drawn for interpretative purposes only.
However, IgE is catabolized by both a direct and indirect pathway. Thus, there are two processes contributing to an average slope. The rate at which IgE leaves the plasma (the FCR) and the rate at which IgE leaves the delay pool $\left(\lambda_{35}\right)$. Because, on the average, $x \%$ of the tracer leaves the plasma by the direct catabolic pathway and $(100-x) \%$ leaves by the indirect pathway (experiencing a delay), an average $t_{1 / 2}$ for circulating IgE can be calculated using the formula:

$t_{1 / 2}=\{(x / 100)(1 / F C R)$

$\left.+[(100-x) / 100]\left(1 / \mathrm{FCR}+1 / \lambda_{35}\right)\right\}(\ln 2)$.

As shown in the last column of Table III, the average $t_{1 / 2}$ for circulating IgE in four normal individuals is $1.79 \pm 0.15 \mathrm{~d}$, whereas for three patients with severe atopy and four patients with HIE the mean $t_{1 / 2}$ values are $4.34 \pm 0.19 \mathrm{~d}(P<0.001)$ and $5.76 \pm 1.29 \mathrm{~d}(P<0.01)$, respectively. In addition, the average $t_{1 / 2}$ is, as expected from the FCR data (Table I and Fig. 5), inversely related to the serum IgE concentrations $(r=-0.880 ; P<0.001)$.

By separating the components of the $t_{1 / 2}$ calculation in Eq. 6 , we can estimate average $t_{1 / 2}$ values for IgE catabolized by each pathway. Thus, it is evident (Table III) that the rates of catabolism via both the direct (intravascular) and the indirect (extravascular, delay) pathways are slower in patients with markedly elevated 
Table II. Extravascular IgE

\begin{tabular}{|c|c|c|c|c|c|c|}
\hline Patient group & Patient & Serum IgE & Intravascular IgE & Total body lgE & Extravascular IgE & IgE \\
\hline & & $\mu g / k g$ & $\mu g / k g$ & $\mu g / k g$ & $\mu g / k g$ & \% extravascular \\
\hline \multirow[t]{5}{*}{ Normals } & L.F. & 0.02 & 1.21 & 5.11 & 3.90 & 76.34 \\
\hline & M.H. & 0.27 & 12.02 & 34.29 & 22.27 & 64.95 \\
\hline & M.N. & 0.02 & 1.09 & 2.72 & 1.63 & 59.90 \\
\hline & R.L. & 0.02 & 0.89 & 3.13 & 2.24 & 71.56 \\
\hline & H.G. & 0.63 & 26.84 & 69.43 & 42.59 & 61.34 \\
\hline Geometric mean & & 0.07 & 3.28 & 10.07 & 6.70 & \\
\hline$X / \div$ relative SEM & & 2.11 & 1.88 & 1.81 & 1.78 & \\
\hline Arithmetic mean & & & & & & 66.82 \\
\hline \pm 1 SEM & & & & & & 2.79 \\
\hline \multirow[t]{4}{*}{ Atopics } & D.M. & 21.83 & $1,090.00$ & $1,749.48$ & 659.48 & 37.70 \\
\hline & G.A. & 90.52 & $3,980.00$ & ND & ND & ND \\
\hline & R.H. & 5.58 & 280.00 & 492.43 & 212.43 & 43.14 \\
\hline & C.H. & 1.81 & 70.00 & 191.30 & 121.30 & 63.41 \\
\hline Geometric mean & & $11.88^{*}$ & $540.00^{*}$ & $548.26^{*}$ & $257.09^{*}$ & \\
\hline$\times / \div$ relative SEM & & 2.33 & 2.12 & 1.69 & 1.50 & \\
\hline Arithmetic mean & & & & & & 48.08 \\
\hline $\pm 1 \mathrm{SEM}$ & & & & & & 15.05 \\
\hline \multirow[t]{5}{*}{ HIE } & C.C. & 20.88 & 970.00 & $1,273.71$ & 303.71 & 23.84 \\
\hline & C.S. & 71.54 & $3,850.00$ & $8,432.22$ & $1,682.37$ & 54.34 \\
\hline & K.Z. & 10.00 & 580.00 & 996.68 & 257.95 & 41.81 \\
\hline & S.W. & 23.73 & 520.00 & ND & ND & ND \\
\hline & T.L. & 137.97 & $5,790.00$ & $7,645.24$ & $1,136.32$ & 24.27 \\
\hline Geometric mean & & $34.50^{*}$ & $1,455.02^{*}$ & $2,117.35^{*}$ & $790.04^{*}$ & \\
\hline$X / \div$ relative SEM & & 1.60 & 1.56 & 1.65 & 1.59 & \\
\hline Arithmetic mean & & & & & & $36.00^{\ddagger}$ \\
\hline \pm 1 SEM & & & & & & 6.00 \\
\hline
\end{tabular}

ND, not determined because of inadequate urine collection. ${ }^{*} P<0.001$ compared with normals. ${ }^{\ddagger} P<0.01$ compared with normals.

$\operatorname{IgE}(P<0.001$, direct; $P<0.05$, indirect). Furthermore, although the proportion of the total body IgE that is catabolized by the indirect catabolic pathway tends to be less in subjects with severe

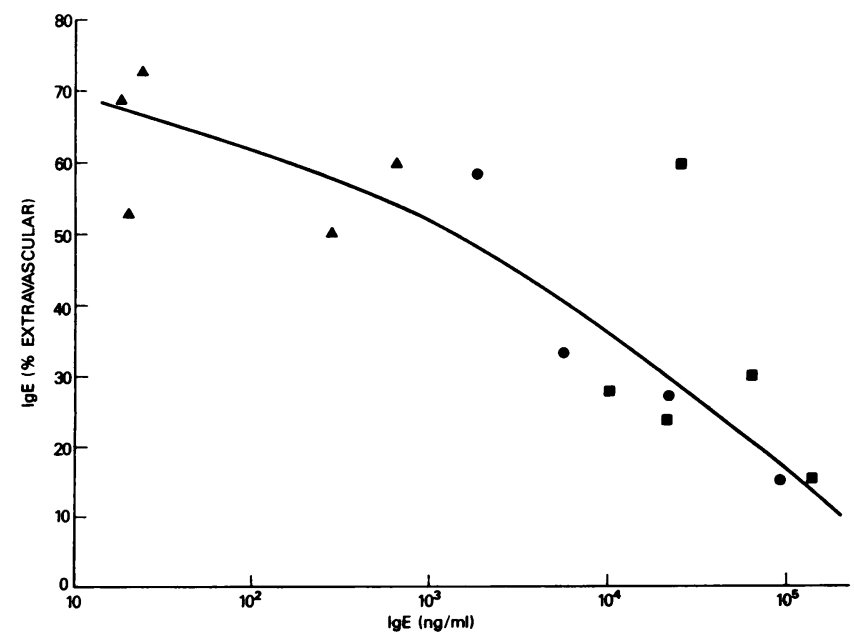

Figure 7. Extravascular IgE as a percentage of the total body IgE is shown as a function of serum IgE levels in the 12 subjects for whom there was adequate data to calculate this parameter. Spearman rankcorrelation coefficient, $r=-0.810 ; P<0.01)$. A line is drawn for interpretative purposes only. atopy $(40 \pm 10 \%)$ and patients with $\mathrm{HIE}(33 \pm 15 \%)$ than in normal volunteers $(54 \pm 7 \%)$, these differences did not reach statistical significance. However, the proportion of the total circulating IgE catabolized via the indirect pathway is inversely related to the serum IgE concentrations $(r=-0.655 ; P<0.05)$, is inversely related to the absolute amount of extravascular $\operatorname{IgE}(r=-0.645$; $P<0.05$ ), and is directly related to the proportion of IgE that is extravascular $(r=0.700 ; P<0.02)$. Thus, those patients with elevated IgE who have an increase in the mass of IgE in the extravascular space (Table II) have a smaller proportion of their IgE catabolized by the indirect pathway. It is therefore possible that the indirect catabolic pathway is located in an extravascular compartment and its ability to handle an increased load starts to become saturated at very high IgE levels. Finally, it is of interest that the indirect catabolic pathway is either saturated or does not exist for the single patient, C.C. (see Table III). This finding may be related to the observation that this is the patient who had evidence of immune complexes on HPLC (see above).

\section{Discussion}

Utilizing purified polyclonal human IgE, we studied IgE metabolism in normal volunteers, in patients with severe atopic disease and markedly elevated IgE, and in patients with HIE. We found that IgE purified from a patient with HIE is catabolized normally (similar to myeloma IgE [2-6]) in normal volunteers. In addition, 


\begin{tabular}{|c|c|c|c|c|c|c|}
\hline Patient group & Patient & Serum IgE & $\begin{array}{l}t_{1 / 2} \text { for } \mathrm{IgE} \text { moving } \\
\text { from pool } 1 \text { to } \\
\text { pool } 3 \text { (direct) }\end{array}$ & $\begin{array}{l}t_{1 / 2} \text { for } \mathrm{IgE} \text { moving from } \\
\text { pool } 1 \text { to pool } 3 \text { via } \\
\text { pool } 5 \text { (indirect) }\end{array}$ & $\begin{array}{l}\text { \% of IgE } \\
\text { catabolized via } \\
\text { indirect path }\end{array}$ & $\begin{array}{l}\text { Weighted "half-life" } \\
\text { for IgE }\end{array}$ \\
\hline & & $\mu g / m l$ & & & & days \\
\hline \multirow[t]{4}{*}{ Normals } & L.F. & 0.02 & 1.24 & 2.30 & 0.70 & 1.98 \\
\hline & M.H. & 0.27 & 1.10 & 2.61 & 0.63 & 2.05 \\
\hline & R.L. & 0.02 & 1.39 & 2.47 & 0.42 & 1.84 \\
\hline & W.G. & 0.62 & 1.12 & 1.50 & 0.40 & 1.27 \\
\hline Mean & & & 1.21 & 2.22 & 0.54 & 1.79 \\
\hline \pm SEM & & & 0.06 & 0.21 & 0.07 & 0.15 \\
\hline \multirow[t]{3}{*}{ Atopics } & D.M. & 21.83 & 3.85 & 7.50 & 0.24 & 4.73 \\
\hline & R.W. & 5.58 & 3.30 & 5.54 & 0.38 & 4.15 \\
\hline & C.W. & 1.81 & 3.15 & 4.84 & 0.59 & 4.15 \\
\hline Mean & & & $3.43^{*}$ & $5.96^{\ddagger}$ & 0.40 & $4.34^{*}$ \\
\hline \pm SEM & & & 0.21 & 0.80 & 0.10 & 0.19 \\
\hline \multirow[t]{4}{*}{ HIE } & C.C. & 20.88 & 3.65 & ND & 0.01 & 3.65 \\
\hline & C.S. & 71.54 & 5.33 & 19.19 & 0.30 & 9.49 \\
\hline & K.Z. & 10.01 & 3.47 & 5.04 & 0.74 & 4.63 \\
\hline & T.L. & 137.97 & 4.62 & 7.01 & 0.27 & 5.27 \\
\hline Mean & & & $4.27^{*}$ & $10.41^{\S}$ & 0.33 & $5.76^{\|}$ \\
\hline \pm SEM & & & 0.43 & 4.43 & 0.15 & 1.29 \\
\hline
\end{tabular}

Data from one normal individual with adequate urine collection did not allow precise determination of the percentage of IgE catabolized by the indirect (extravascular) pathway. Urine collection was inadequate from one person with atopy and one subject with HIE. ND, Not determined. ${ }^{*} P<0.001$ compared with normals. ${ }^{\ddagger} P<0.01$ compared with normals. ${ }^{\S}$ Not significant, but for all patients with elevated IgE $(n=6)$ the mean value is $8.19 \pm 2.05$ ( $P<0.05$ compared with normals). " $P<0.05$ compared with normals.

we found no substantial difference in the manner in which patients with HIE and patients with severe atopy catabolize IgE. These findings argue strongly against the possibility that patients with HIE have a unique defect in either the structure or the catabolism of IgE. Upon analysis of the metabolic data with the SAAM-27 program, we were able to construct a minimal compartmental model of IgE metabolism that fits the data from all three subject groups and is compatible with known biochemical and physiological information concerning IgE. From this analysis it is apparent that IgE metabolism is distinctive in at least four ways: (a) IgE is catabolized at a higher fractional rate than other immunoglobulins; $(b)$ the IgE FCR is inversely related to the serum IgE concentration and, under the limiting condition of high serum IgE concentrations, is catabolized at a fractional rate similar to that of other immunoglobulins; (c) IgE is catabolized by an extravascular as well as an intravascular pathway; and $(d)$ the fraction of the total IgE that is extravascular as well as the proportion of IgE that is catabolized by the extravascular pathway are inversely related to the serum IgE concentration.

It is clear from the data in this study and from data published previously $(2,4-7,20)$ that in normal individuals IgE is catabolized at a fractional rate $\sim 10$ times that of $\operatorname{IgG}, 4$ times that of $\operatorname{IgM}$ and $\operatorname{IgA}$, and 2 times that of $\operatorname{IgD}$. One explanation for this observation is that IgE is subject, not only to the catabolic processes that affect all immunoglobulins, but also to a superimposed catabolic mechanism specific for IgE. Support for this view comes from a consideration of the relationships between immunoglobulin concentrations and immunoglobulin catabolism. For IgG, the FCR in individuals with normal IgG levels is $0.06 \pm 0.01$ but is increased in patients with very high IgG levels $(0.15-0.17)$. As presented in this study, normal serum IgE con- centrations are associated with high FCR $(0.52 \pm 0.06)$, which are decreased at high IgE concentrations to $0.15 \pm 0.02$. A similar situation has been described for $\operatorname{IgD}(20,21)$. Finally, for $\operatorname{IgA}$ $(22,23)$ and $\operatorname{IgM}(24)$ no concentration effects have been seen. These immunoglobulins display FCR $(0.25 \pm 0.02$ and $0.19 \pm 0.01$, respectively) similar to those encountered with the other immunoglobulins when high immunoglobulin levels are present. Thus, there appears to be a baseline FCR that affects all immunoglobulins (FCR $=0.15-0.25$ ) and is decreased in the case of IgG and increased in the case of IgD and IgE, presumably because of the presence of additional concentration-dependent factors. The IgG situation has been explained (25) by postulating the existence of saturable protective sites that shield IgG from catabolism and therefore function as a "negative" catabolic pathway. By the same token, we postulate an additive ("positive") catabolic pathway for IgD and IgE.

The FCR for IgE in normal volunteers measured in this study was smaller than that reported earlier $(0.52 \pm 0.06$ vs. $0.94 \pm 0.08$ in reference 6 ). This is mostly due to the inclusion (in our current model) of pool 2 for nonbindable ${ }^{125} \mathrm{I}$-IgE, which allowed us to exclude the effect of rapidly degradable and nonphysiologic IgE. A second discrepancy from the previous data on IgE metabolism relates to differences in the $t_{1 / 2}$ values in the two studies. In the present study the $t_{1 / 2}$ obtained is shorter than that obtained previously. This relates to the fact that the $t_{1 / 2}$ for IgE was previously determined by measuring the slope of the terminal portion of the plasma die-away curve (6) on the assumption that the disappearance of tracer from the plasma during this period of time is determined by a single exponential decay. We found, however, that IgE catabolism occurs via both an indirect (extravascular, delay) route as well as by a direct (intra- 
vascular) catabolic route. Thus, for IgE, the terminal portion of the plasma die-away curve is determined by at least two separate metabolic processes. On this basis, we have chosen to calculate the average $t_{1 / 2}$ (Table III) using an expression containing the weighted (average) exponential decay for each pathway (Eq. 6).

An interesting and important corollary of the variation in FCR with serum IgE levels is a necessary reassessment of the estimation of relative IgE synthetic rates. As shown in Table I, inferences concerning IgE synthetic rates based on serum IgE levels can overestimate true synthetic rates by as much as 6.5fold if FCR is not taken into account.

The metabolism of IgE is also distinctive from that of the major immunoglobulin classes in that there is evidence for extravascular catabolism. This was first suggested in a prior study (6), but has been more clearly delineated in the compartmental analysis performed here. The current study demonstrates that a satisfactory fit of the data required the inclusion of an extravascular catabolic pool (pool 5) as well as an extravascular exchangeable pool (pool 4). Of interest, the modeling analysis allowed estimation of the relative amounts of IgE in the intravascular and extravascular pools as well as the proportion of IgE catabolized by each pathway. As shown in Table II, the absolute amount of extravascular IgE increases as the serum IgE increases $(r=0.991 ; P<0.001)$. However, it is important to note that the proportion of the total IgE that is extravascular decreases as the serum IgE concentration increases $(r=-0.810 ; P<0.01)$ (Table II and Fig. 6), suggesting that the rise in serum IgE is greater than the increase in available binding sites. A related interesting observation is that the proportion of the $\operatorname{IgE}$ that is catabolized by the extravascular pathway is inversely related to the serum IgE concentration and is directly related to the proportion of IgE that is extravascular (see Table III). These relationships suggest that part of the excess catabolism of IgE may be due to the presence of IgE receptors that function as extravascular catabolic sites. In addition, the convergence of the in vitro binding data and the computer modeling analysis supports the hypothesis that the extravascular exchangeable binding pool may consist of one or more types of IgE receptor and that these receptors may be part of the extravascular nonexchangeable catabolic pool. Because of its high affinity and large number, the mast cell IgE receptor is a likely candidate for such a role both in regard to IgE binding and in terms of IgE catabolism. However, IgE receptors of lower affinity on other cell types may also be important.

Our finding that the absolute amount of extravascular IgE increases as the serum IgE level increases (Table II) is compatible with published observations that patients with elevated IgE have increased numbers of IgE receptors on circulating basophils (26) and lymphocytes $(27,28)$. In addition, up-regulation of IgE receptors (after exposure to high concentrations of IgE) has been observed in vitro for rat basophil leukemia cells (29) and for mouse macrophages and lymphocytes (30), suggesting that this may be a general finding for cells bearing IgE receptors.

In spite of the above arguments, at least two objections can be raised to the idea that the high-affinity IgE receptor of the mast cell is an important extravascular catabolic site. First, there are several studies indicating that cutaneously injected IgE turns over very slowly in comparison to the turnover of IgE moving through the extravascular catabolic pathway as described in this study. Thus, the calculated $t_{4 / 2}$ of skin-sensitizing activity after administration of reaginic serum (31) and the $t_{\psi_{2}}$ of ${ }^{131} \mathrm{I}-\mathrm{IgE}$ injected subcutaneously (32) are long (8.5-14 d) in comparison to our estimated $t_{y_{2}}$ for IgE in normal volunteers $(1.8 \mathrm{~d}$ overall and $2.2 \mathrm{~d}$ by the indirect catabolic pathway). Furthermore, subcutaneously injected IgE has been shown to block PrausnitzKüstner reactivity for prolonged periods ( $>2$ wk) (33). This discrepancy is partially mitigated by the fact that in yet another study (34), the $t_{1 / 2}$ of subcutaneously injected reaginic serum was estimated to be 4.2-4.9 d. In addition, it should be kept in mind that while the disappearance of Prausnitz-Küstner reactivity and the catabolism of IgE are closely related, they are not the same phenomena. Finally, the connective tissue mast cell is only one of several types of tissue mast cells (35) and those in the skin probably represent a relatively minor proportion of the total body IgE high-affinity binding sites.

A second objection to the hypothesis that the high-affinity IgE receptor of the mast cell may mediate IgE catabolism is that monomeric IgE bound to the rat high-affinity IgE receptor of the basophilic leukemia cell is not catabolized $(36,37)$. However, although this cell line resembles mucosal mast cells (35), there are marked ultrastructural differences between the two cell types and there may also be differences in the manner in which these cells handle IgE monomers. In addition, it is not known whether other cell types with high-affinity receptors for IgE (e.g., bone marrow-derived mast cells, connective tissue mast cells, and basophils) can catabolize monomeric IgE. Finally, as mentioned above, there are other cells with low-affinity IgE receptors, specifically macrophages $(30,38)$, lymphocytes $(27,28,39)$, and eosinophils (40) in which the issue of IgE catabolism has not been studied and thus remain as possible sites of catabolism.

In conclusion, evidence has been presented that supports a model of IgE catabolism in which IgE is catabolized at rates greatly exceeding that of the other immunoglobulins and is catabolized via intravascular and extravascular catabolic pathways. In addition, the model indicates that the FCR of IgE is inversely related to the serum IgE concentration and, under the limiting condition of elevated serum IgE levels, is similar to that of the other immunoglobulins. This suggests that IgE is catabolized in normal individuals via a nonsaturable catabolic pathway common to all immunoglobulins as well as by a saturable IgE-specific pathway. Finally, the model indicates that the proportion of the total IgE that is extravascular and the proportion of IgE catabolized by the extravascular pathway are inversely related to the serum IgE concentration. These findings suggest that the extravascular catabolic pathway may be related to one or more types of IgE receptor.

\section{Acknowledgments}

The authors thank Dr. Teruko Ishizaka for help in the characterization of the ${ }^{125} \mathrm{I}$-IgE (binding to human basophils), the National Institute of Allergy and Infectious Diseases clinical associates who have contributed to the evaluation and care of these patients, and Ms. Babette Wilkerson for typing the manuscript.

\section{References}

1. Ishizaka, K., and T. Ishizaka. 1983. Immunology of IgE-mediated hypersensitivity. In Allergy, Principles and Practice. 2nd edition. E. Middleton, Jr., C. E. Reed, and E. F. Ellis, editors. C. V. Mosby Co., St. Louis, MO. 43-73.

2. Ogawa, M., O. R. McIntire, K. Ishizaka, T. Ishizaka, W. D. Terry, and T. A. Waldman. 1971. Biologic properties of $\mathrm{E}$ myeloma proteins. Am. J. Med. 51:193-199. 
3. Waldmann, T. A., W. Strober, S. H. Polmar, and W. D. Terry. 1972. IgE levels and metabolism in immune deficiency diseases. In Biological Role of the Immunoglobulin E System. J. Ishizaka and Dayton, editors. National Institute of Child Health and Human Development, Bethesda, MD. 247-258.

4. Waldmann, T. A., A. lio, M. Ogawa, O. R. McIntyre, and W. Strober. 1976. The metabolism of IgE. J. Immunol. 117:1139-1144.

5. Iio, A., W. Strober, S. Broder, S. H. Polmer, and T. A. Waldmann. 1977. The metabolism of IgE in patients with immunodeficiency states and neoplastic conditions. J. Clin. Invest. 59:743-755.

6. lio, A., T. A. Waldmann, and W. Strober. 1978. Metabolic study of human IgE: evidence for an extravascular catabolic pathway. J. Immunol. 120:1696-1701.

7. Waldmann, T. A., W. Strober, and R. M. Blaese. 1971. Metabolism of immunoglobulins. In Progress in Immunology: First International Conference of Immunology. B. Amos, editor. Academic Press, Inc., New York. 891-903.

8. Donabedian, H., and J. I. Gallin. 1983. The hyperimmunoglobulin E recurrent-infection (Job's) syndrome. Medicine (Baltimore). 62:195208.

9. Berman, M., and M. F. Weiss. 1978. SAAM Manual. In DHEW Publication No. 27 (NIH). Laboratory of Theoretical Biology, National Cancer Institute, National Institutes of Health, Bethesda, MD.

10. Ring, J. 1983. Plasma histamine concentrations in atopic eczema. Clin. Allergy. 13:545.

11. Dreskin, S. C., P. K. Goldsmith, and J. I. Gallin. 1985. Immunoglobulins in the hyperimmunoglobulin E and recurrent infection (Job's) syndrome. J. Clin. Invest. 75:26-34.

12. Goldsmith, P. K. 1981. A highly sensitive enzyme-linked immunosorbent assay for human immunoglobulin $\mathrm{E}$ : comparison of microtiter plate and disk methodologies. Anal. Biochem. 117:53-60.

13. Bradford, M. M. 1976. A rapid and sensitive method for the quantitation of microgram quantities of protein utilizing the principle of protein-dye binding. Anal. Biochem. 72:248-254.

14. Reference deleted in proof.

15. Berman, M., E. Shahn, and M. F. Weiss. 1962. The routine fitting of kinetic data to models: a mathematical formalism for digital computers. Biophys. J. 2:275-287.

16. Berman, M., W. F. Beltz, P. C. Greif, R. Chabay, and R. C. Boston. 1983. CONSAM User's Guide. Laboratory of Mathematical Biology, National Cancer Institute, National Institutes of Health, Bethesda, MD.

17. Berman, M. 1982. Kinetic analysis and modeling: theory and applications to lipoproteins. In Lipoprotein Kinetics and Modeling. M. Berman, S. M. Grundy, and B. V. Howard, editors. Academic Press, Inc., New York. 3-35.

18. Boston, R. C., P. C. Greif, and M. Berman. 1982. CONSAM (Conversational version of the SAAM modeling program). In Lipoprotein Kinetics and Modeling. M. Berman, S. M. Grundy, and B. V. Howard, editors. Academic Press, Inc., New York. 437-460.

19. Phair, R. D. 1982. The role of kinetic modeling in physiology. In Lipoprotein Kinetics and Modeling. M. Berman, S. M. Grundy, and B. V. Howard, editors. Academic Press, Inc., New York. 37-40.

20. Waldmann, T. A., and W. Strober. 1969. Metabolism of immunoglobulins. Prog. Allergy. 13:1-110.

21. Rogentine, G. N., Jr., D. S. Rowe, J. Bradley, T. A. Waldmann, and J. L. Fahey. 1966. Metabolism of human immunoglobulin D (IgD). J. Clin. Immunol. 45:1467-1478.

22. Strober, W., R. D. Wochner, M. H. Barlow, D. E. McFarlin, and
T. A. Waldmann. 1968. Immunoglobulin metabolism in ataxia telangiectasia. J. Clin. Invest. 47:1905-1915.

23. Delacroix, D. L., K. B. Elkon, A. P. Geubel, H. F. Hodgson, C. Dive, and J. P. Vaerman. 1982. Changes in size, subclass, and metabolic properties of serum immunoglobulin $\mathrm{A}$ in liver diseases and in other diseases with high serum immunoglobulin A. J. Clin. Invest. 71:358367.

24. Barth, W. G., R. D. Wochner, T. A. Waldmann, and J. L. Fahey. 1964. Metabolism of human gamma macroglobulins. J. Clin. Immunol. 43:1036-1048.

25. Brambell, R. W. R., W. A. Hemmings, and I. G. Morris. 1964. A theoretical model of $\gamma$-globulin catabolism. Nature (Lond.). 203:13521355.

26. Malveaux, F. J., M. C. Conroy, N. F. Adkinson, Jr., and L. M. Lichtenstein. 1978. IgE receptors on human basophils. J. Clin. Invest. 62:176-181.

27. Spiegelberg, H. L., R. D. O'Connor, R. A. Simon, and D. A. Mathison. 1979. Lymphocytes with immunoglobulin E Fc receptors in patients with atopic disorders. J. Clin. Invest. 64:714-720.

28. Spiegelberg, H. L., and R. A. Simon. 1981. Increase of lymphocytes with $\mathrm{Fc}$ receptors for $\mathrm{IgE}$ in patients with allergic rhinitis during the grass pollen season. J. Clin. Invest. 68:845-852.

29. Furuichi, K., J. Rivera, and C. Isersky. 1985. The receptor for immunoglobulin $\mathrm{E}$ on rat basophilic leukemia cells: effect of ligand binding on receptor expression. Proc. Natl. Acad. Sci. USA. 82:15221525.

30. Daeron, M., and K. Ishizaka. 1986. Induction of $\mathrm{Fc}_{\mathrm{e}}$ receptors on mouse macrophages and lymphocytes by homologous IgE. J. Immunol. 136:1612-1619.

31. Cass, R. M., and B. R. Andersen. 1968. The disappearance rate of skin-sensitizing antibody activity after intradermal administration. $J$. Allergy. 42:29-35.

32. Ishizaka, K., and T. Ishizaka. 1971. IgE immunoglobulins of human and monkey. In Biochemistry of the Acute Allergic Reaction. K. F. Austen and E. L. Becker, editors. Blackwell Scientific Publications, Oxford. 13-32.

33. Geha, R. S., B. Helm, and H. Gould. 1985. Inhibition of the Prausnitz-Kustner reaction by an immunoglobulin $\epsilon$-chain fragment synthesized in E. coli. Nature (Lond.). 315:577-578.

34. Fireman, P., M. Boesman, and D. Gitlin. 1967. Disappearance of intradermally administered plasma immunoglobulins and skin-sensitizing antibodies. J. Allergy. 40:304-316.

35. Seldin, D. C., S. Adelman, K. F. Austen, R. L. Stevens, A. Hein, J. P. Caulfield, and R. G. Woodbury. 1985. Homology of the rat basophilic leukemia cell and the rat mucosal mast cell. Proc. Natl. Acad. Sci. USA. 82:3871-3875.

36. Isersky, C., J. Rivera, S. Mims, and T. J. Triche. 1984. The fate of IgE bound to rat basophilic leukemia cells. J. Immunol. 122:19261936.

37. Furuichi, K., J. Rivera, C. Isersky. 1984. The fate of IgE bound to rat basophilic leukemia cells. III. Relationship between antigen-induced endocytosis and serotonin release. J. Immunol. 133:1513-1520.

38. Finbloom, D. S., and H. Metzger. 1982. Binding of immunoglobulin $\mathrm{E}$ to the receptor on rat peritoneal macrophages. J. Immunol. 129:2004-2008.

39. Melewicz, F. M., J. M. Plummer, and H. L. Spiegelberg. 1982. Comparison of the $\mathrm{Fc}$ receptors for $\mathrm{IgE}$ on human lymphocytes and monocytes. J. Immunol. 129:563-569.

40. Capron, M., A. Capron, J.-P. Dessaint, G. Torpier, S. Gunnar, O. Johansson, and L. Prin. 1981. Fc receptors for IgE on human and rat eosinophils. J. Immunol. 126:2087-2092. 